\title{
Algunos aspectos sobre la pesca tradicional en las costas de la Ajarquía (Costa del Sol Oriental de Málaga)
}

La zona Este de la actual provincia de Málaga, enmarcada por las sierras de Alhama, Tejeda y Almijara al Norte y el mar Mediterráneo al Sur, constituye la comarca de la Ajarquía (o Axarquía, como gusta actualmente decir), del árabe شرق denadas UTM aproximadas son: latitud Norte, entre 4.065 y 4.095 ; longitud Oeste, entre 385 y 430.

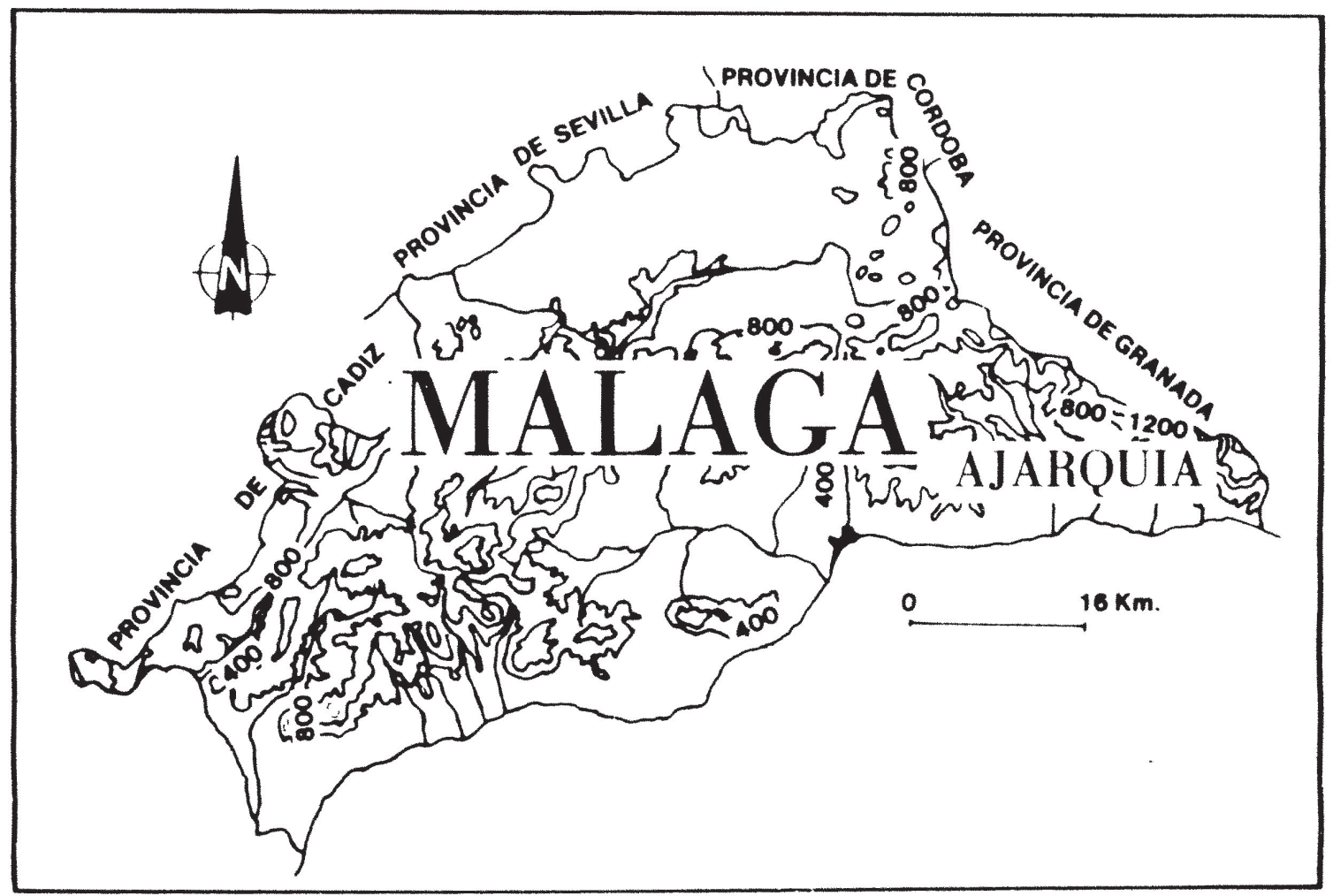

FIG. 1.-Situación geográfica de la Ajarquía

En líneas generales esta comarca se configura como una especie de anfiteatro abierto al mar, de complicada orografía que se resuelve en un paisaje laberíntico. Las sierras del Norte superan en sus cotas más altas los 2.000 metros de altura, desde donde en sucesivos escalones se desciende hasta las aguas del Mediterráneo. 
La presencia del mar constituye uno de los hechos fundamentales de la Ajarquía. Hoy conforma un paisaje de urbanizaciones y negocios turísticos, relegando a un plano muy secundario las viejas actividades pesqueras que, en otro tiempo, al lado de la agricultura y el pastoreo, integraron los sectores productivos más importantes.

Ya los textos clásicos mencionan la importante actividad industrial que se derivaba de la pesca en nuestras aguas. Esta actividad estaba orientada especialmente a la exportación del garum o pasta salada de pescado que se enviaba a Roma y, antes incluso, a Atenas. Parece ser que buena parte del Sur peninsular se dedicaba a estos trabajos y, si bien es verdad que los centros de producción más notables se ubican fuera de la Ajarquía actual, la arqueología ha venido a demostrar su existencia en esta zona, destacando, según lo que hoy conocemos, Torrox en la elaboración de este producto. Próximos a los hornos cerámicos se han excavado dos saladeros y un muelle sobre el río homónimo ${ }^{1}$.

Estrabón, autor que escribe su obra pocos años antes del cambio de era, recogiendo en ella muchos datos geográficos de escritores (Homero, Estesícoro, Heródoto, Eforo, Eratóstenes, Polibio, Posidonio, entre otros), dedica el Libro III de su Geografía a Iberia en que hace reiteradas referencias a las tareas derivadas de la pesca (III, 1,6;2,6;2,7;3,1;4,6; 5,8; 5,9). También Plinio en su Naturalis Historia, obra terminada poco antes de su trágica muerte en la erupción del Vesubio (año 79), describe diversos aspectos referidos a la pesca en nuestras aguas mediterráneas. Hablando del garum (XXXI, 94) dice que «el mejor se obtiene del pez escombro (caballa, Scomber scumbrus) [...]. Se le conoce con el nombre de sociorum. Dos congios [un congio $=3,25$ litros] no se pagan con menos de mil monedas de plata [...]. Los escombros se pescan en las costas de la Mauritania y de la Baetica». En otro párrafo (XXXII, 146) nos informa de «el pez colias pariano y sexitano, de la Baetica (Sexi = Almuñécar)», y de que esta localidad granadina limítrofe con la Ajarquía era «célebre en tiempos muy atrás por las excelencias de sus conservas de pescado, de su garum». Pero el pescado más apreciado era la dorada (Sparus aurata), llamado zeus y también faber (IX, 68).

Parece ser que el chanquete (Aphya minuta), pez perteneciente a la familia de los góbidos, ya era conocido en estos tiempos antiguos ${ }^{2}$. Plinio nos informa de que el garo, antes de fabricarse con caballa, se obtenía de

S. Giménez ReYNA, «Memoria arqueológica de la provincia de Málaga», Informes y Memorias núm. 12 (Madrid, 1946).

2 Resulta de sumo interés el artículo de Alfonso CANALES, «Chanquetes», Jábega, Revista de la Diputación malagueña, 11 (1975). 
un pececillo denominado apua por los latinos y que se dice aphyen en griego. ¿Tal vez esta especie se corresponde con nuestro chanquete? Según A. Canales parece ser que sí, e incluso cita una receta tomada de la tesis doctoral del farmacéutico Carlos López Herrera sobre la fórmula de elaborar el garum donde no faltan las apuas.

Este pequeño pez se captura por medio de redes de malla muy fina y en forma de copo (ver lám. I, b). Es normal que con mallas tan finas queden atrapadas, además del chanquete, las crías de otras especies, especialmente sardina y boquerón. El color ligeramente rosado del chanquete permite diferenciarlo al entendido.

El problema de esta pesca indiscriminada resulta ya viejo en nuestras costas. El libro de Ordenanças de la mvy noble y mvy leal Ciudad de Málaga, impreso por Juan René (Málaga, 1611), recoge la siguiente disposición:

Yten porque por ysperiençia se a visto que las crías del pescado se pierden e se matan con el tiempo que no se aprovechan dello por ende ordenamos y mandamos que las jáuegas que pescaren que los copos que desde oy día se hizieren hagan las mallas que quepan por ellas el dedo segundo de la mano e para ello tengan los alcaldes medida de una sortija para que conforme a ella sean las dichas mallas e no se hagan de otra manera.

La España musulmana hizo un consumo notable de pescado. Se practicó la pesca fluvial, como se recoge en Le Calendrier de Cordoue ${ }^{3}$. En las costas del mar Mediterráneo (también en la zona atlántica) los pescadores

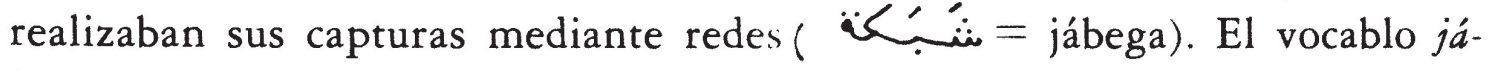
bega lo recoge Manuel Alvar ${ }^{4}$ en documentación aragonesa del siglo XVI para designar probablemente «herpil» (red de tomiza con mallas anchas, destinado a llevar paja, melones, etc.). Este arabismo con que hoy se conoce un tipo tradicional de barca, según el mismo autor, llegará a identificarse con la red de la almadraba y, por extensión, a las gentes que ellas trabajaban. Serán conocidos por el nombre de jabegueros según numerosos testimonios:

Hazense tambien muchas ramadas o chozas que llaman chancas, en que se recogen los xabegueros y jente común de la pesquerías.

3 Le Calendrier de Cordoue, ed. Ch. Pellat (Leiden, 1961).

4 M. Alvar, «Historia lingüística de Jábega», Jábega, 11 (1975).

5 De la obra de A. Solé, Los pícaros de Conil y Zabara (Cádiz, 1966). (Citado por M. Alvar en el artículo de la nota anterior.) 
Según algunas fuentes parece ser que los jabegueros gozaban de cierta mala fama, llegando a ser calificados como «la hez de la república». Alguna reminiscencia parece haberse pegado en la significación despectiva de nuestro «marengo», nombre con que se designa a los pescadores de estas costas en la actualidad (fig. 2).

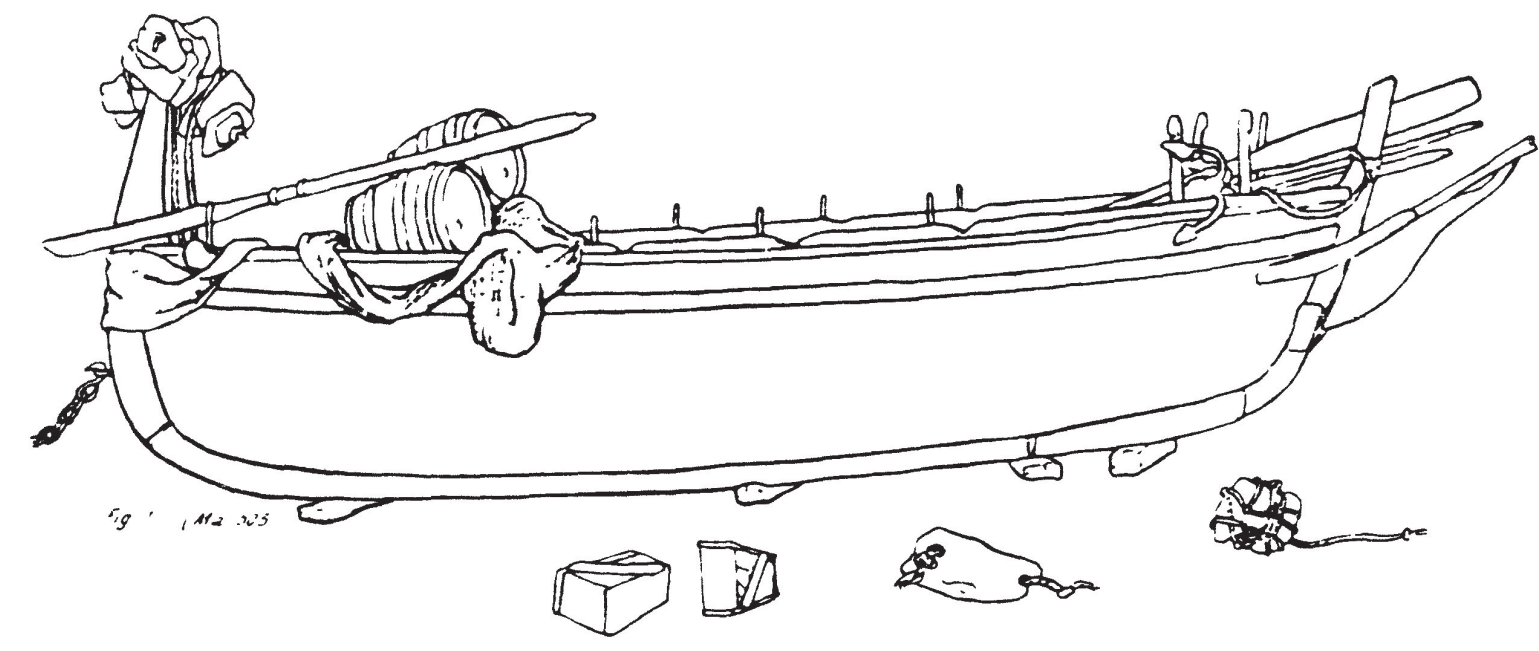

Jábega con dos proas

Fig. 2.-Jábega según el ALEA de M. Alvar y col. (Univ. de Granada y CSIC, 1961-1973).

La almadraba se emplea para la captura de atunes cuando este pez pasa del Atlántico al Mediterráneo en los meses de primavera. Todavía hoy se practica este método en las costas del Estrecho. En nuestra provincia de Málaga existían almadrabas en funcionamiento hasta mediados de este siglo. Miranda y Rivera ${ }^{6}$ denomina a este sistema de almadraba de vista o tiro: «vista» porque se divisaban los bancos de atunes desde las atalayas, y «tiro» por la forma de maniobrar sobre las redes para aprisionar los peces.

Volviendo otra vez a la época musulmana, hemos de señalar que en las poblaciones costeras era importante el consumo que se hacía de pescado fresco. Al-Saqati en el primer cuarto el siglo XIII recogía la reglamentación justa que regía la vida del zoco, proporcionándonos noticias sobre la vida cotidiana en los mercados. Veamos dos muestras:

(76) Cómo han de vender los pescadores.

Porfíe [hasta conseguir] que los vendedores de pescado no entreguen el de la víspera mezclado con el fresco, ni conserven pescado del día anterior como no sea salado. El de la víspera se venderá aparte y lo mismo se hará con el fresco. Esto incluye también a aquellos que lo venden frito o guisado.

6 Miranda y Rivera, La pesca del atún en España (Madrid: Instituto Oceanográfico Español, 1923). 
Cuidado que han de tener los esportilleros.

Prohibirá que nadie lleve un pescado en la mano, a no ser si estuviera en una bolsa, para que no pueda rozar los vestidos de la gente. A todo aquel que fuera hallado llevándolo sin envolver se le pondrá el pescado en el seno, como escarmiento ?

Después de la conquista, muchas de estas disposiciones de la b̧isbat al$s \bar{u} q$, tuvieron su reflejo en los Libros de Ordenanças que reglamentaron la vida de las ciudades incorporadas a los reinos cristianos, tal como ocurre con Málaga ${ }^{8}$ y Vélez-Málaga 9 .

Anteriormente, según las noticias transmitidas por al-Idridì (siglo XII), a una distancia de 8 parasangas al Este de la ciudad de Málaga, se hallaba situada la pesquería de Bizilyana (Bezmiliana, próxima al actual Rincón de la Victoria), que disponía de posadas, baños y almadrabas, donde se capturaban grandes peces, posiblemente atunes ${ }^{10}$.

La tradición pesquera, la preparación de pescado seco y de salazones se perpetúa con el correr de los años. Vélez disfrutará de la importante renta del tigual o tegual, un bien de propios que beneficia las arcas del Cabildo municipal según disposiciones regias. Tanto las actas capitulares como otras fuentes documentales (Catastro de Ensenada, entre ellas), nos confirman la continuidad de las actividades pesqueras y sus industrias derivadas. También lo hacen las disposiciones de las Ordenanzas citadas al reglamentar los distintos aspectos concernientes a pesca y actividades complementarias. Así se dice:

7 AL-SAQATİ, Kitāb fì ādāb al-hisba (Libro del buen gobierno del zoco), estudio y traducción de Pedro Chalmeta Gendrón, Al-Andalus, XXXII y XXXIII $(1967,1971)$. El zabazoque de la época Omeya o almotacén de los Abbasíes era el encargado de cumplir y hacer cumplir la bisba, evitando los fraudes en la vida del mercado.

8 Ordenanças de la mvy noble y mvy leal ciudad de Málaga. Imprimiólas Juan René. Año de 1611.

9 Ordenanças de la muy noble ciudad de Vélez-Málaga de la Cruz. (A)rchivo (M)unicipal de (V)élez. [En adelante: Ordenanzas... (A.M.V.)]. Se trata de una recopilación anónima y sin fecha, que recoge posiblemente algunos aspectos que proceden de las Ordenanzas de la ciudad de Málaga, a la vez que las disposiciones municipales veleñas y sus viejas Ordenanzas, ratificadas por la reina doña Juana en 1511. Entre las mercedes aquí recogidas que los Reyes Católicos hicieron para los propios de la ciudad, se confirma en 1491 la renta del «tigual», impuesto sobre el pescado fresco y salado que saliese de la ciudad.

10 J. E. LOPEZ DE COCA, «Bezmiliana. Un despoblado en tierras malagueñas (siglos XV-XVI)», Cuadernos de Estudios Medievales, I (1973). 
[...] que no se pueda vender por los dichos regatones el pescado cecial ${ }^{11}$ a ojo, salvo remojado e por peso que sea de fierro e con garfios, e sin balanças por evitar los engaños que fazen so pena de seisçientos mrvds para los propios de la ciudad ${ }^{12}$.

Al mismo tiempo se prohibe a los forasteros elaborar anchoa, consignándose que ésta se haga de buena calidad y que se envase en barriles. El plano de la Torre de la Mar de Vélez (figs. 3 y 4), dibujado por Joachin de Villarroel en 1785, recoge dentro del bastión artillado los talleres de toneleros y barrileros, poniendo de relieve la importancia de estos artesanos. Algo más lejos se ubica el almacén de la sal que también era secadero. Poco más de medio siglo más tarde Madoz, en su Diccionario ${ }^{13}$, nos dice que en Torre del Mar existe unn almacén destinado para depósito de la sal de bastante solidez y capacidad» y «una casa secadero de fábrica moderna».

Respecto a la fabricación de anchoa y sardina anchovada, las Ordenanzas señalan lo siguiente:

Por quanto en la dicha ciudad se faze anchova para vender obrada para cargar e llevar por la mar de aquí adelante se guarde e conserve lo siguiente: Primeramente que ningun vezino ni forastero sea osado de fazer anchova dentro de la ciudad ni en sus arravales salvo fuera dellos por el mucho daño que viene a los vezinos del mal olor que de aquello procede é por ser la ciudad peligrosa de pestilencia, se debe escusar todo mal olor e suciedad de las casas e calles de los vezinos ${ }^{14}$.

11 Cecial $=$ Pescado seco y curado al aire.

12 Ordenanzas... (A.M.V.), fol. 185.

13 P. MADOZ, Diccionario Geográfico-Estadístico de España y sus posesiones de ultramar, Madrid, 1847. Voz Torre del Mar.

14 Ordenanza... (A.M.V.), fol. 205. 


\section{Torre de ha llar de velez}

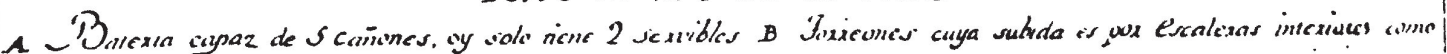

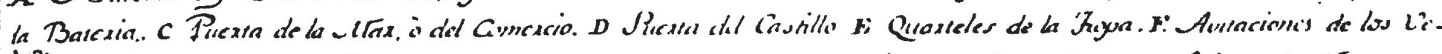

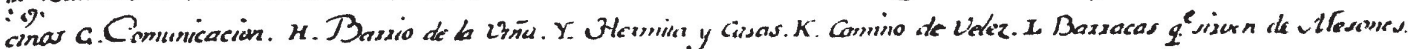

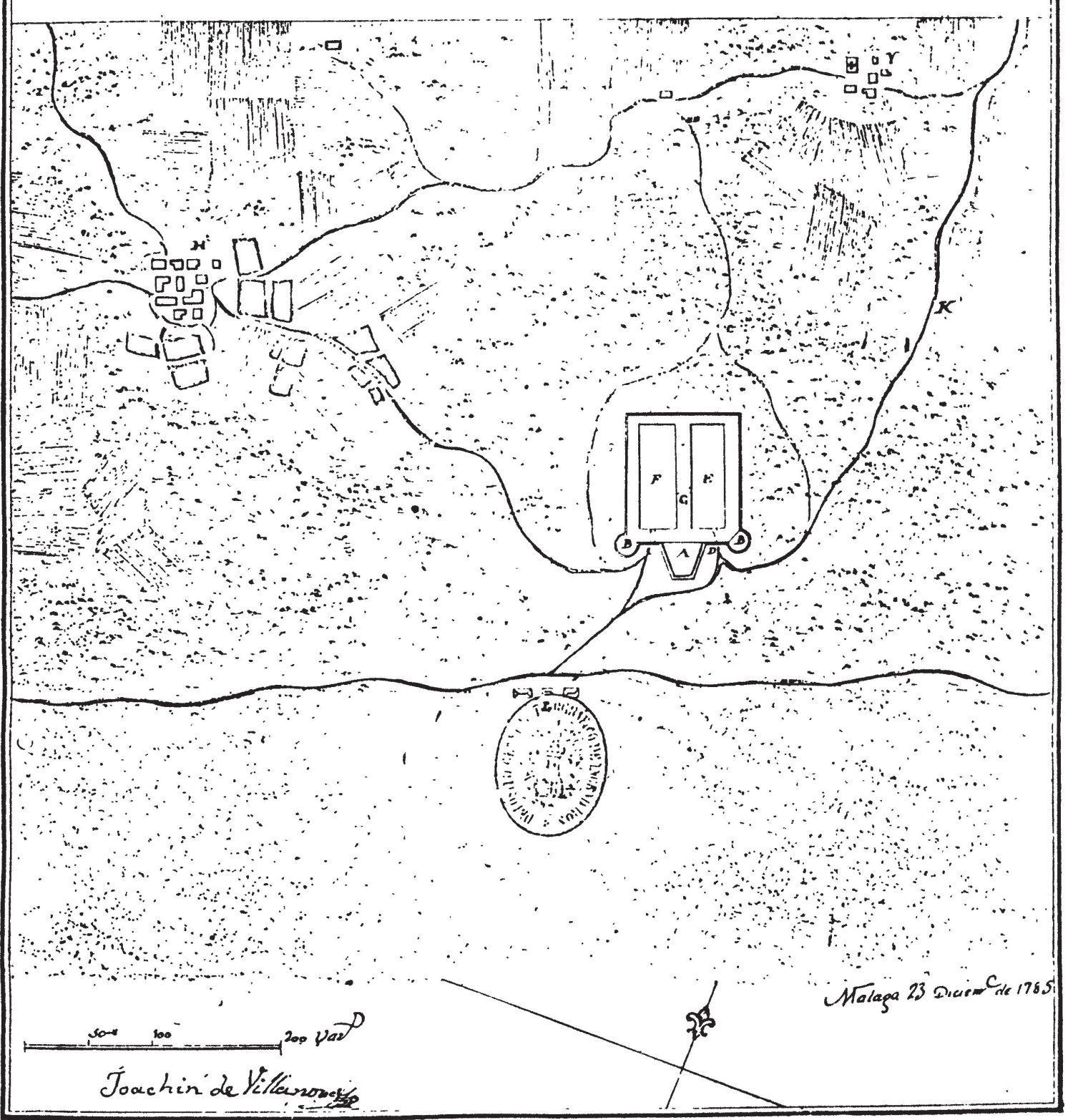

Fig. 3.-Plano general de Torre del Mar con sus sistemas defensivos. Año 1785. 


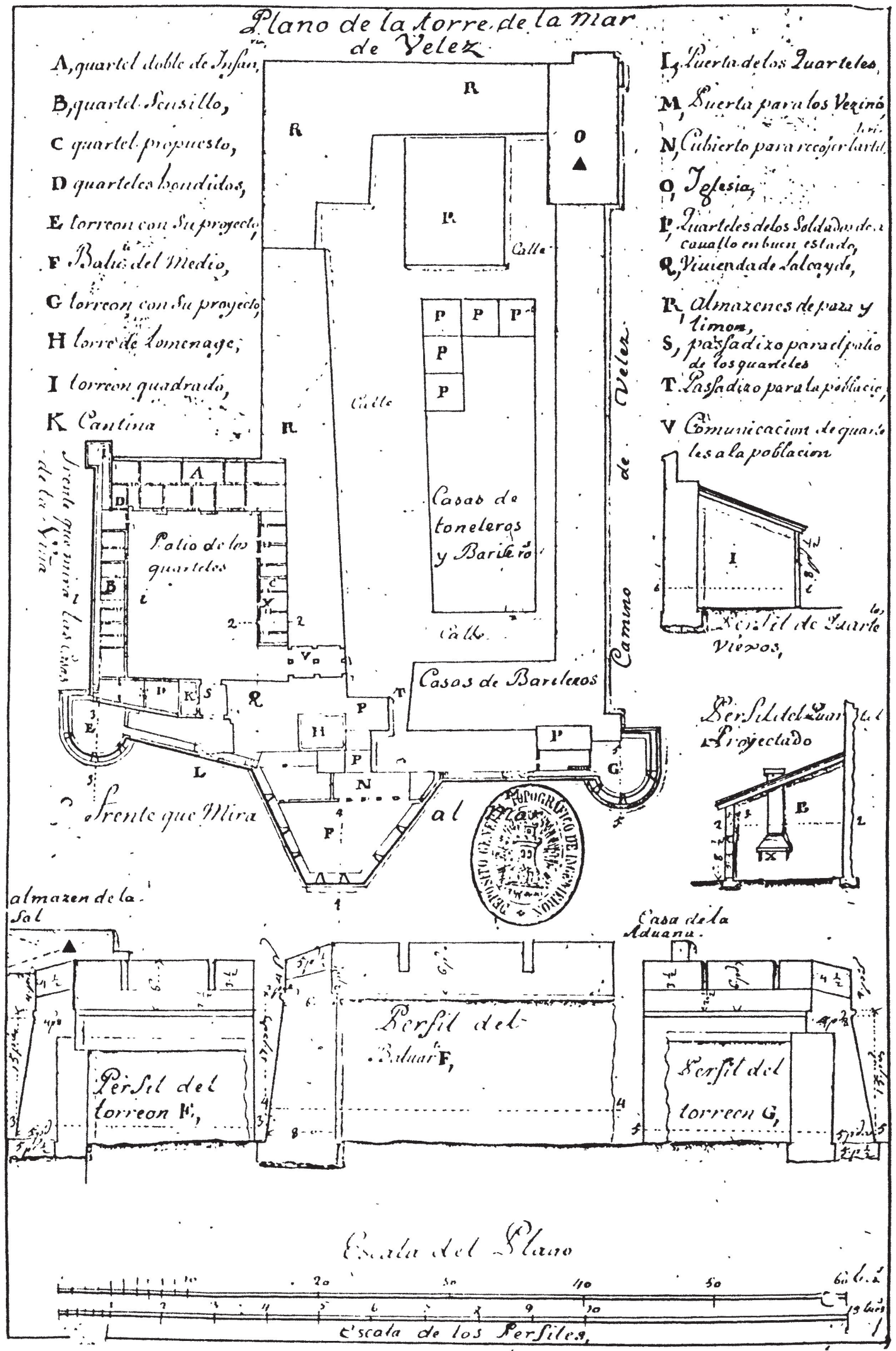

Fig. 4.-Detalle del plano de la figura n. ${ }^{\circ}$ : Su identificación con el plano actual viene dada por la situación de la iglesia y el almacén de sal, actual saladero en desuso. 


\section{LA PESCA CON JÁBEGA Y CON BOLICHE (JÁBEGA PEQUEÑA)}

La jábega es una larga red (el tipo denominado «jábega real» llega a medir casi 270 metros) compuesta de un copo y dos bandas o pernadas. Las bandas se continúan por cabos largos de los que se tira desde tierra, tarea ésta que realizan los jabegotes o marengos, mientras que la voz jabeguero designa al pescador de jábega ${ }^{15}$.

Los tamaños de esta red varían notablemente ya que este arte de pesca se ha practicado en las costas gallegas y en todas las del Sur y el Mediterráneo, incluyendo el Norte de África. Según su tamaño se diferencian los siguientes tipos:

a) jábega real, la mayor

b) media jábega

c) jábega chica o boliche.

Esta red, independientemente de su tamaño, se divide en seis o siete tramos. Desde los extremos de las bandas, donde se colocan unos palos conocidos como calones, se distinguen -en una jábega real- las siguientes partes diferenciadas por el tamaño de la malla y la longitud del tramo:

1. alar o claro, de $45 \mathrm{~ms}$. de longitud y malla de $13 \mathrm{cms}$. de lado.

2. rigal, reinal o reigal, $58 \mathrm{~ms}$. y malla de $25 \mathrm{cms}$.

3. docena, $88 \mathrm{~ms}$. y $14 \mathrm{cms}$. de malla.

4. cazarete, $45 \mathrm{~ms}$. y $75 \mathrm{mms}$. de malla.

5. gola, 9 ms. y malla decreciente en tres tramos que pasan de 45 a $15 \mathrm{mms}$.

6. copo, $28 \mathrm{~ms}$. y malla de $14 \mathrm{mms}$.

7. corona, de $3 \mathrm{~ms}$. de longitud y malla de $12 \mathrm{mms}$, rematada a veces por un pedazo de red doble, el rabiche, de malla doble para dotar de mayor resistencia al cierre del arte.

En las relingas se colocan flotadores y plomos. En la relinga superior es donde se amarran los corchos (panecillas), con una distancia de aproximadamente 2 metros, pero se apiñan a la entrada de la boca del copo para facilitar la captura. En la relinga inferior se colocan plomos.

De los calones, mediante dos betas, se amarran largos cabos de los que se tira para halar el copo. Para operar con este arte, uno de los cabos se deja en tierra y, desde la embarcación con la red a bordo, se va largando la jábega hasta cercar un espacio, llevando a tierra el otro extremo de la red. En ese momento se puede comenzar a halar. La operación de halar se realiza en nuestra costa tirando de los cabos mediante el empleo de cingletas o trallas, hechas de cuerdas con un corcho o madera en un extremo que se

15 M. Moliner, Diccionario de uso del español (Madrid, 1967). 
arrolla a los cabos de la jábega para tirar de ellos. Llegado el copo a la playa se extrae y clasifica el pescado capturado mediante el uso del salabardo o sencillamente a mano.

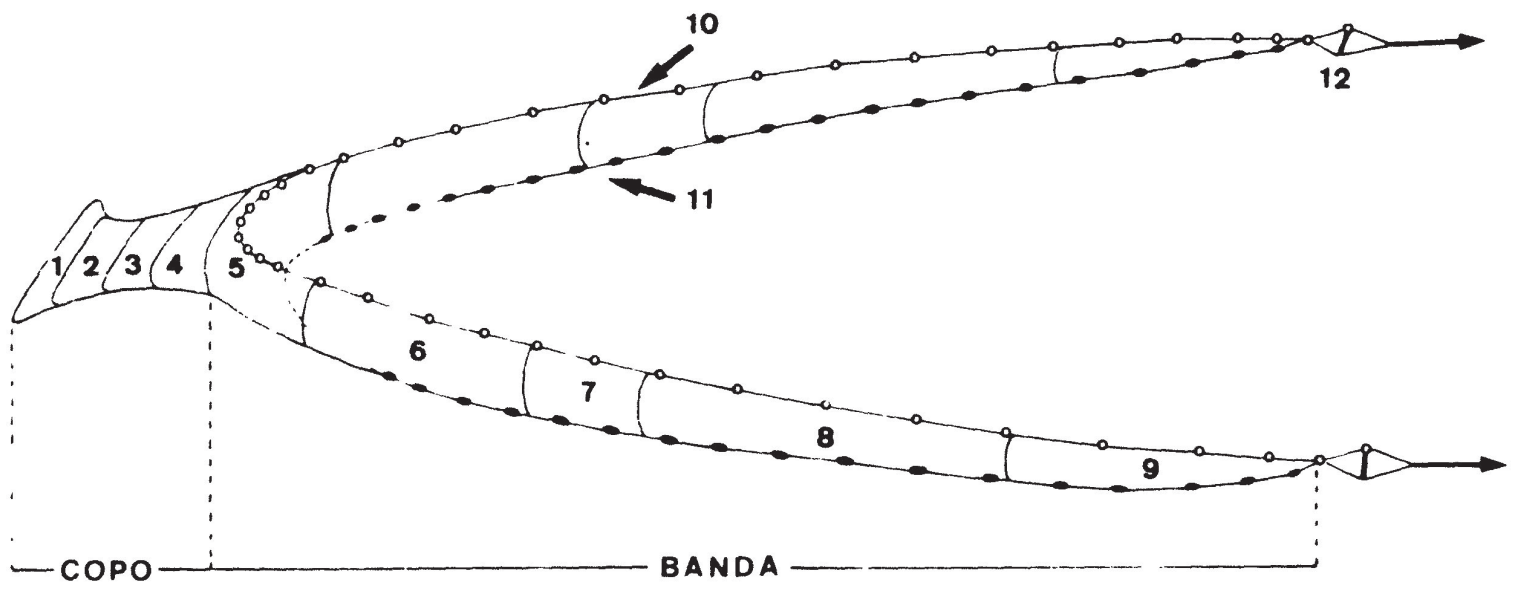

Fig. 5.-Arte de pesca de boliche: 1: coronel o corona borda. 2: coronilla o corona (1, 2 y 3). 3: cajeta. 4: caja (1, 2 y 3). 5: batidero (con calima). 6: arcanales. 7: cazaretes. 8: rigales. 9: claros. 10: relinga alta o de corchos. 11: relinga baja o de plomos. 12: calones (tomado de A. García et al. Jábega n. ${ }^{\circ}$ 33.-Modificado).

La manera tradicional de fabricar las redes se reglamenta detalladamente en las Ordenanzas de la muy noble ciudad de Vélez-Málaga y que recogemos aquí:

La orden y cosas que an de guardar los cordoneros, es la siguiente:

[...] Iten, que todos los dichos oficiales e rederos que tengan sus braças, e cobdos sellados del fiel de la ciudad, so la dicha pena de seiscientos mrvs.

-, que las redes dozenas, é filgas ${ }^{16}$ é colares ${ }^{17}$, é galluderas ${ }^{18}$, é laboretas, é redes de tenares para pescar coruinas, é xauegas con sus espesos, é cada vna de estas redes lleue su cuento e mallas de braças como es dicho, so la dicha pena.

- que dozena de doze lleue çiento é cincuenta mallas enfrente, é doze en cabezas en todo, é dose brasas en luengo, el filo desta de catorze o quinze dobles á la libra, e que sea de buen zerro ${ }^{19}$, é puro, é que el que no fiziere ansi, pague la pena de seiscientos mrvs.

-, que dozena de catorze lleue ciento e cinquenta mallas enfrente, é catorze carreras en todo, é que sea el filo de á deziocho e de dezisiete dobles de la libra, so la dicha pena.

16 Hace referencia a la pesca con fisga, arpones para capturar grandes peces.

17 Se suele emplear esta voz entre pescadores y marineros en el sentido de sumergir o hundir.

18 Galludos (Squalus blainvillei y Squalus acanthias). Red gallundera = red empleada en la pesca de cazones y otros escualos. utilización.

19 El zerro (cerro) es el manojo de lino o cáñamo después de preparado para su 
-, que dozena de a dies y seis lleue ciento é cinquenta mallas enfrente, é desiseis carreras en todo lleue este mismo filo, so la dha. pena.

[Siguen las mismas normas para las docenas de 18, 20, 22, 24, 26 y 28 carreras y bajo las mismas penas.]

- que estas docenas que sean todas por su cuento en ygual grado, tanto al comienço, como al medio, como al acabamiento, é su filo bueno e sin arte, é que el que lo contrario hiziere incurra en la dicha pena.

-, que se llaman firgas, que lleuen cinquenta mallas enfrente y treinta y seis carreras en todo, é dende arriba lleue onze braças é media en luengo, que sea de zerro y estopa un filo, y otro de otro, é la que fuere de estopa que sea quemada por falsa, é que el que la fiziere o mandare fazer, pague la dicha pena de suso.

-, que las redes de cazonal, que se llaman tollares ${ }^{20}$, que se lleue veinte mallas enfrente, con los malleros, que fue uso y costumbre con sesenta braças en luengo, é que sea de cerro y estopa vn filo, y otro de otro, y el que viniere demandando cerro puro que se lo den por su justo precio, y el que lo fiziere de estopa que le sea quemado por falsa y pague la dicha pena de suso.

- , que las redes de galladeras, con que se pescan los cazones, é todo pexe de cuero ${ }^{21}$ que lleue veinte é dos mallas enfrente, é sessenta braças en luengo, é que sea de buen cerro puro, é el que la fiziere de cerro e estopa, que pierda la tal obra, é al que la fiziere de estopa pura que sea quemada por falsa, é pague la dicha pena de suso.

-, que las redes de caçonal, que se llaman laboretes, que sean fechas de tres filos, vno y otro de otro, é lleue dies y seis mallas enfrente, é sessenta mallas enfrente, é al que viniere demandando cerro puro que se lo den por su justo precio, y el oficial que lo contrario fiziere que pague la dicha pena de suso. E que si la red fuere de estopa pura, que le sea quemada por falsa.

-, que las auares [¿alares?] para pescar coruinas, que se fagan de buen cerro é que se vendan por justo precio, é quien lo contrario hiziere pague la dicha pena de suso. -, que la red que se llama de claro ques la red que fuere de cien mallas enfrente é çinquenta braças en largo, é sea fecha de cerro y estopa, é si fuere de estopa pura, que sea quemada por falsa, é pena la dicha pena de suso.

-, que los espesos de la xabega que llaman alcanelas ${ }^{22}$ que lleue ciento y cinquenta mallas enfrente, é doze braças en luengo, é que sea de buen zerro é estopa, é si fuere de estopa pura que sea quemada por falsa, é pena de dicha pena de suso.

-, que el caçarat ${ }^{23}$ de la xabega que lleve dozientas e sessenta mallas enfrente, é doze brazas en luengo, é que sea de buen zerro é estopa, é si fuere de estopa pura, ó de cánamo podrido, que sea quemada por falsa, é pague la pena susodicha.

-, que las redes que se llaman de raygual ${ }^{24}$ que lleue ciento e setenta mallas enfrente, é veinte y dos braças en luengo, é si lo fiziere de estopa que sea quemada, é pague la dicha pena de suso.

20 Tolla $=$ mielga, pintarroja. La mielga común es un tiburón de pequeñas dimensiones ( 80 a $90 \mathrm{cms}$. de longitud). Vive en el Mediterráneo y es comestible.

${ }^{21}$ Se refiere sin duda a los peces que en lugar de escamas poseen dentículos dérmicos, como el tiburón o la raya.

22 Arcanelas.

23 Cazaretes.

24 Rigal. 
-, que qualquier armador que uiniere demandando xabega de cerro puro, que se la den por justo precio, é si la fizieren de zerro y estopa, que sea quemada é pague la dicha pena de suso, é sea obligado á le fazer otra á su costa.

-, que qualquier armador de qualquiera suerte que fuere, que pueda comprar cañamo é rompello en su casa para lo que menester quiere para su labrar é armazon e lo dé a labrar a los maestros é oficiales que estan examinados por el dicho veedor, ó veedores, y no puedan hazer mas de lo que para su armazon menester ouiere é lo no puedan vender filo ni redes a otra ninguna persona, pues que no lo sabe ni es su oficio, é si le fuere prouado pague la dicha pena de suso.

-, que las rederas que fagan redes como las suelen fazer en los tiempos mas antiguos que las fazian de los armadores é de los cordoneros, é la que lo contrario hiziere incurra en la pena susodicha ${ }^{25}$.

En las costas de la Ajarquía, al lado de artes modernas, se sigue usando esta secular forma de pesca, si bien relegada hoy a niveles mínimos, compensados a menudo por el atractivo turístico. Se emplea el boliche, red barredera, que se ha conocido también como «jábega chica» por su menor tamaño. Aunque su longitud es variable, suele andar cerca de las 50 brazas. Este arte está compuesto de una serie de piezas diferenciadas por el número de mallas (ver lám. II, a), que en el fondo del copo se espesan hasta 4,5 pasadas por cada cuadrado de un $\mathrm{cm}$. de lado. Se arma con corchos en la relinga alta y plomos en la baja, y se cala mediante un orinque, echándola al agua desde una barca. En las betas, para evitar que la cuerda arrastre por el fondo, hay varias boyas llamadas levas. Se cala dejando un cabo en tierra, dando un cerco y halando posteriormente de los dos cabos. Generalmente de cada cuerda tiran media docena de hombres ayudándose de trallas o cingletas (fig. 6).

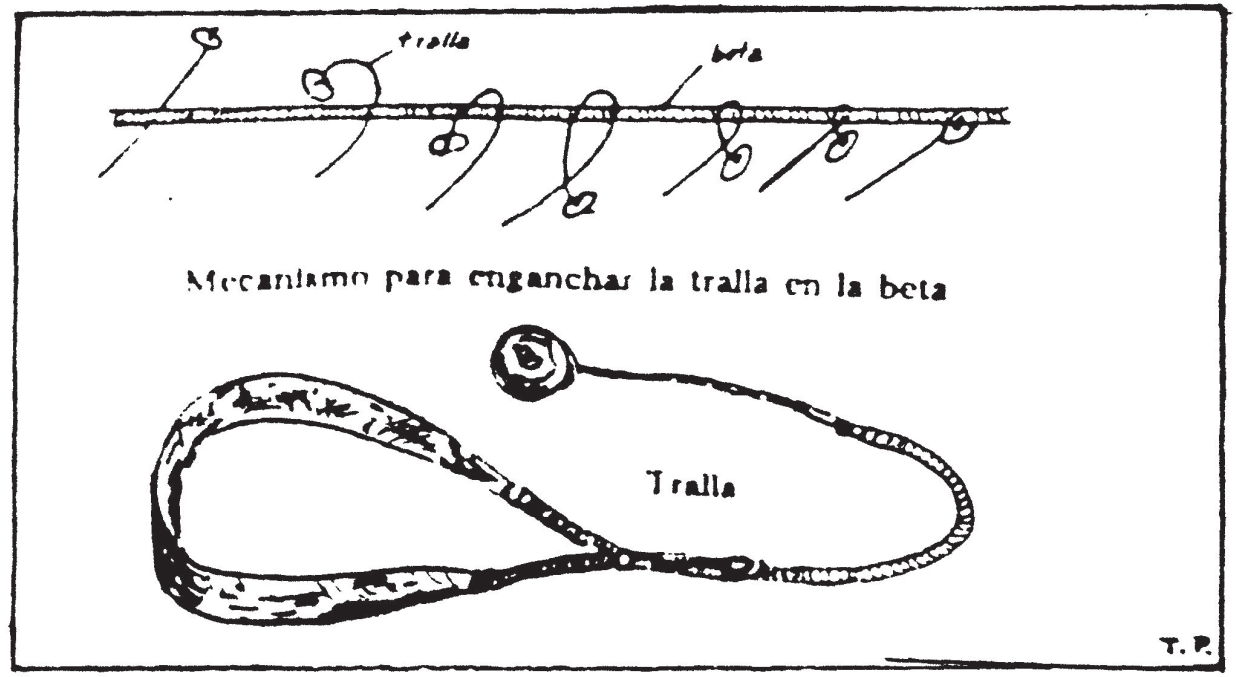

FIG. 6.- Tralla o cingleta y su forma de enganchar en la beta (según publ. del CEP de Vélez-Málaga).

${ }^{25}$ Ordenanzas... (A.M.V.), fols. 314 a 319. 
La barca tradicional que se ha empleado para esta forma de pesca en nuestras costas, recibe también el nombre de jábega. Se trata e una barca con espolón, sin palos ni velas, gobernada con un remo. Todo el hueco de la barca se destina al arte (fig. 7).

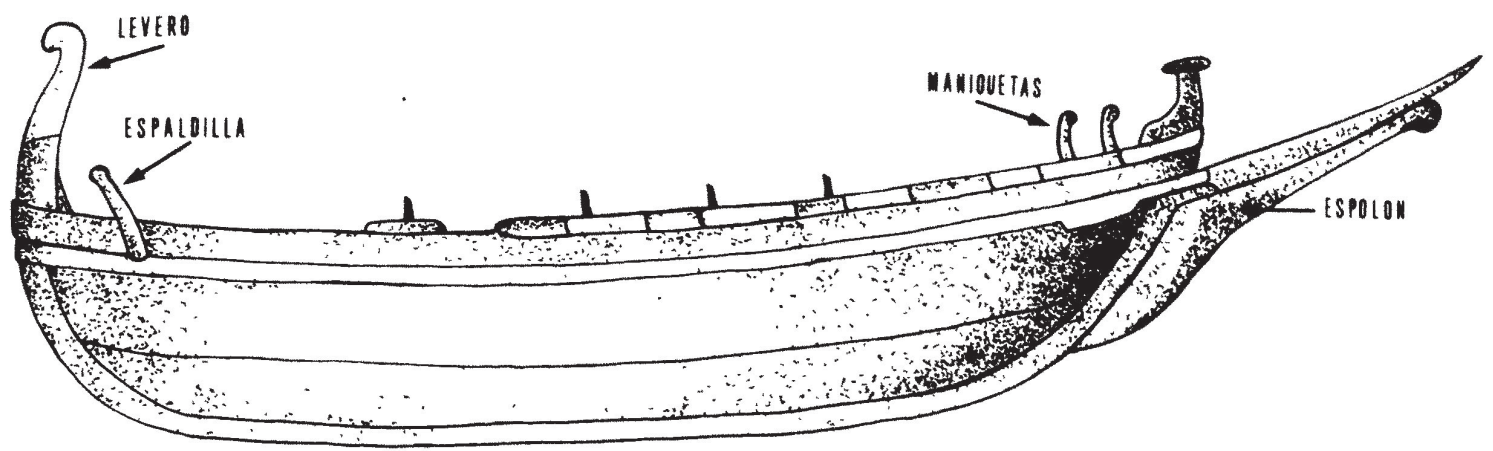

FiG. 7.-Partes más relevantes de la jábega utilizada en nuestras costas.

Antiguamente, desde el Rincón de la Victoria hasta Nerja se pescaba el bonito por el procedimiento de a la vista, es decir, viendo la pesca desde tierra. Esta barca, para evitar que cayese al agua el encargado de localizar la pesca, tienen la proa muy saliente y un bidón en cada banda. Un cesto llamado morrón se colocaba en un remo para avisar que se precisaba gente para halar el arte. Las barcas denominadas jábegas prácticamente han desaparecido y el «copo» se realiza hoy con pequeñas embarcaciones dotadas de motor (fig. 8).

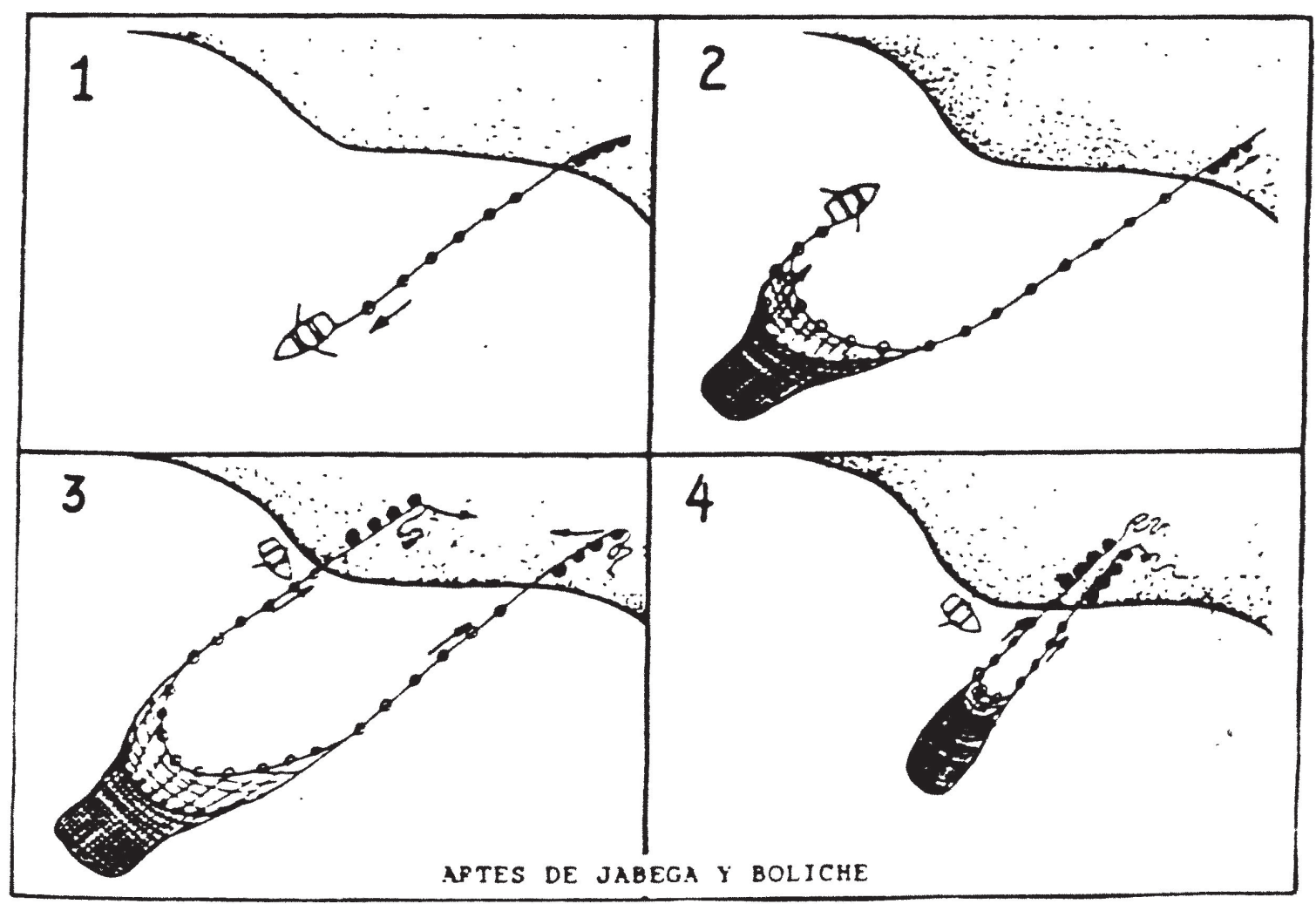

FIG. 8.-Desarrollo del proceso de pesca con artes de jábega y boliche (según publ. del CEP de Vélez-Málaga). 

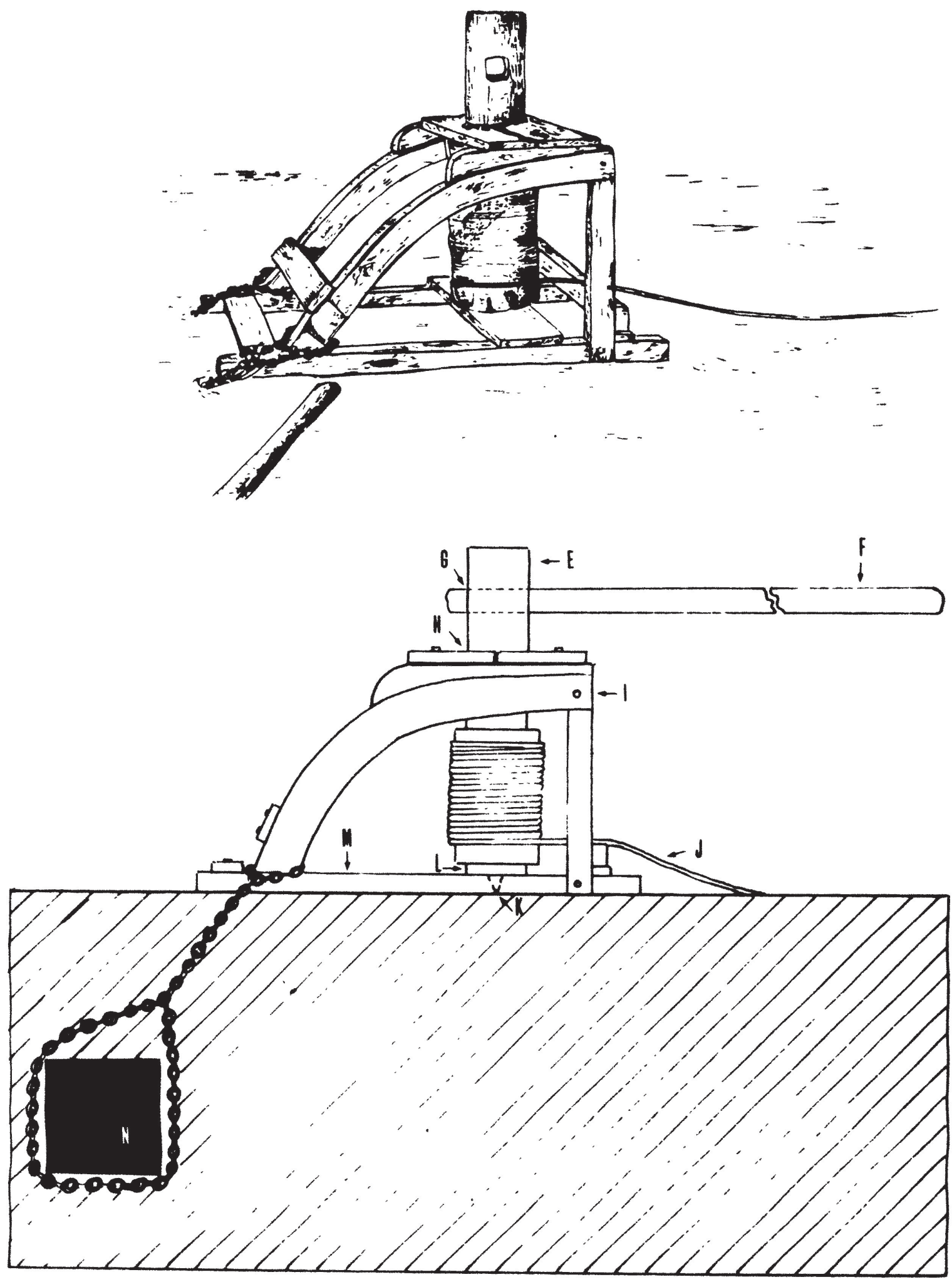

FIG. 9. - Torno para varar las embarcaciones y su corte esquemático: E) cabeza. F) palanca. G) boquete. H) cuello. I) laterales. J) cable. K) pinzote. L) soporte. M) base. N) muerto (enterrado en la playa). (Según la terminología marenga de Lagos). 

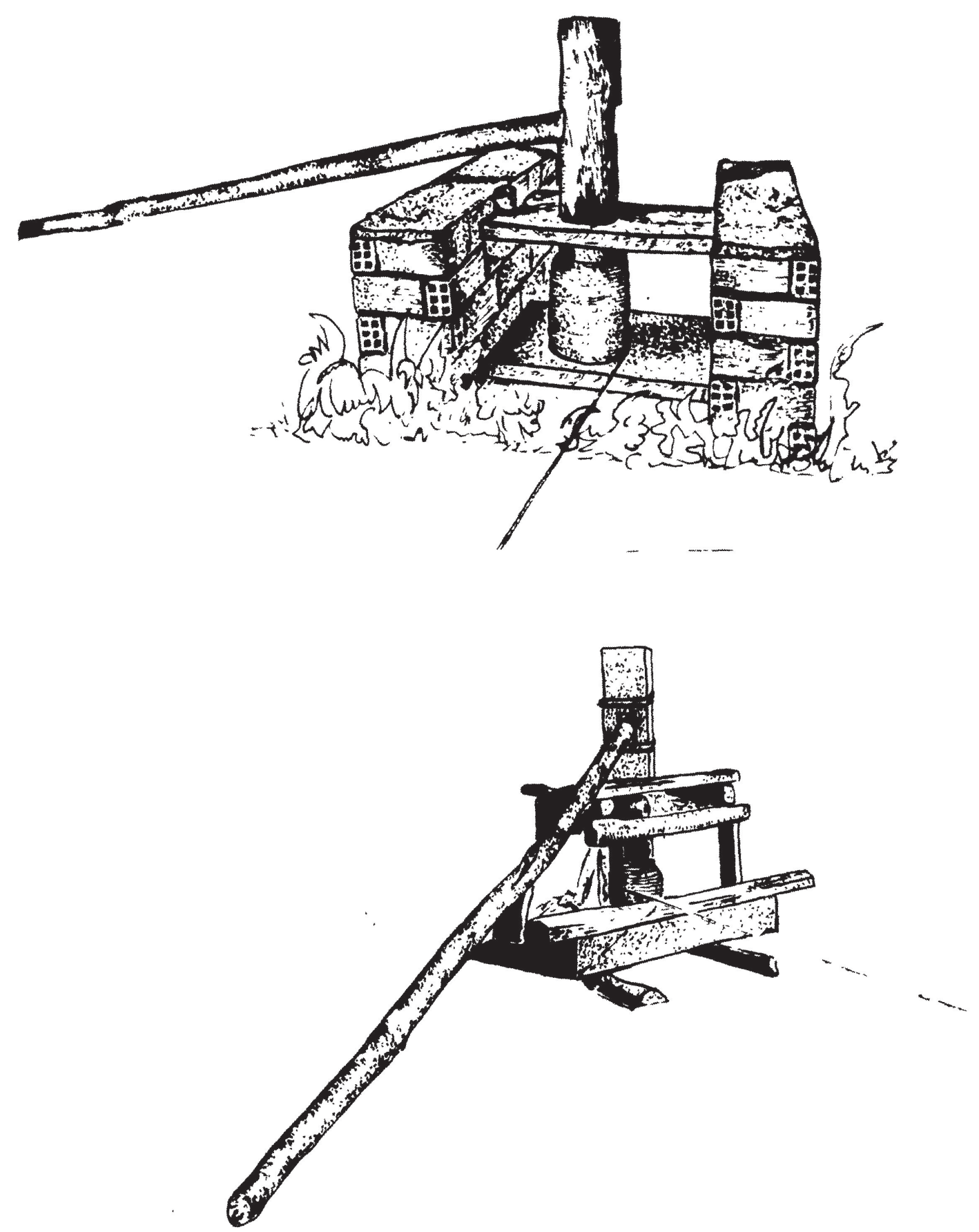

FIG. 10.-Dos modelos distintos de torno para varar (Playa y caladero de Benajarafe). 
Nos resta, para concluir, señalar la forma que tienen nuestros pescadores de varar las barcas. El torno que usan está construido normalmente de recias maderas de encina, roble u olivo. Se ancla firmemente en tierra mediante un muerto, objeto pesado y enterrado en la playa y amarrado mediante cadenas o cables al torno (fig. 9).

Con la palanca introducida en el boquete de la cabeza - algunos están dotados de dos palancas - se gira en el pesado trabajo de recoger el cable que arrastra la barca a la playa. Existen tornos construidos totalmente de tubos de hierro, y otros en los que alternan la madera con la obra de albañilería. En la actualidad se ven sustituidos por motores eléctricos, situados en las casillas de enseres, que facilitan el trabajo (fig. 10).

\author{
EFRÉN FERNÁNDEZ LAVANDERA \\ MANUEL E. OROZCO REDONDO \\ CARMELO-MiLlán FERNÁNDEZ ROdRÍGUEZ
}

Este trabajo sobre la actividad pesquera en las costas de la Ajarquía (Málaga) se fundamenta principalmente en el estudio de una recopilación de las Ordenanzas Municipales de la ciudad de Vélez-Málaga, pero recogiendo, a la vez, una breve reseña histórica de la pesca en el Sur de la Península Ibérica. Al mismo tiempo se hace referencia a aquellas industrias artesanales que complementaban las capturas pesqueras. La información directa de los marengos que, casi de forma testimonial, siguen practicando estos ancestrales métodos, también es recogida.

This paper devoted to the fishing acticity in the Ajarquía coastal area (Málaga) draws its information from these main sorces. The by laws issued by the Vélez-Málaga Town Council, and a historical reference to fishing activity in southern Spain. References to croft industries connected to fishing are also included. We ave finally gathered some first-hand information provided by te drag net fishermen who, here and there, still use these old fishing methods. 


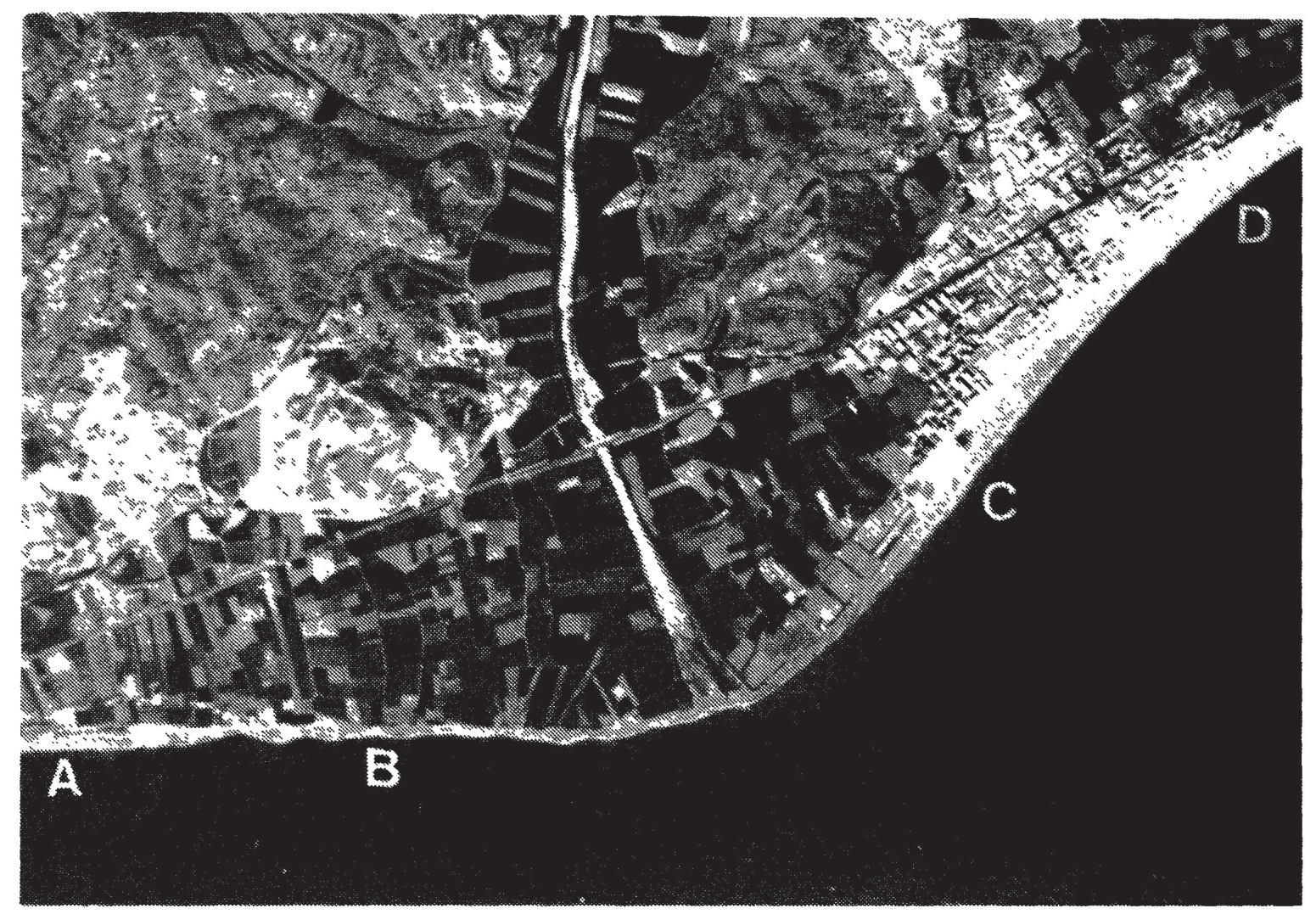

LÁM. I, a. Vista aérea de la flecha deltaica del río Vélez. Se señalan los siguientes caladeros que todavía hoy se utilizan: A) Playa Hornillos. B) Bajamar. C) El Faro. D) El Morro.

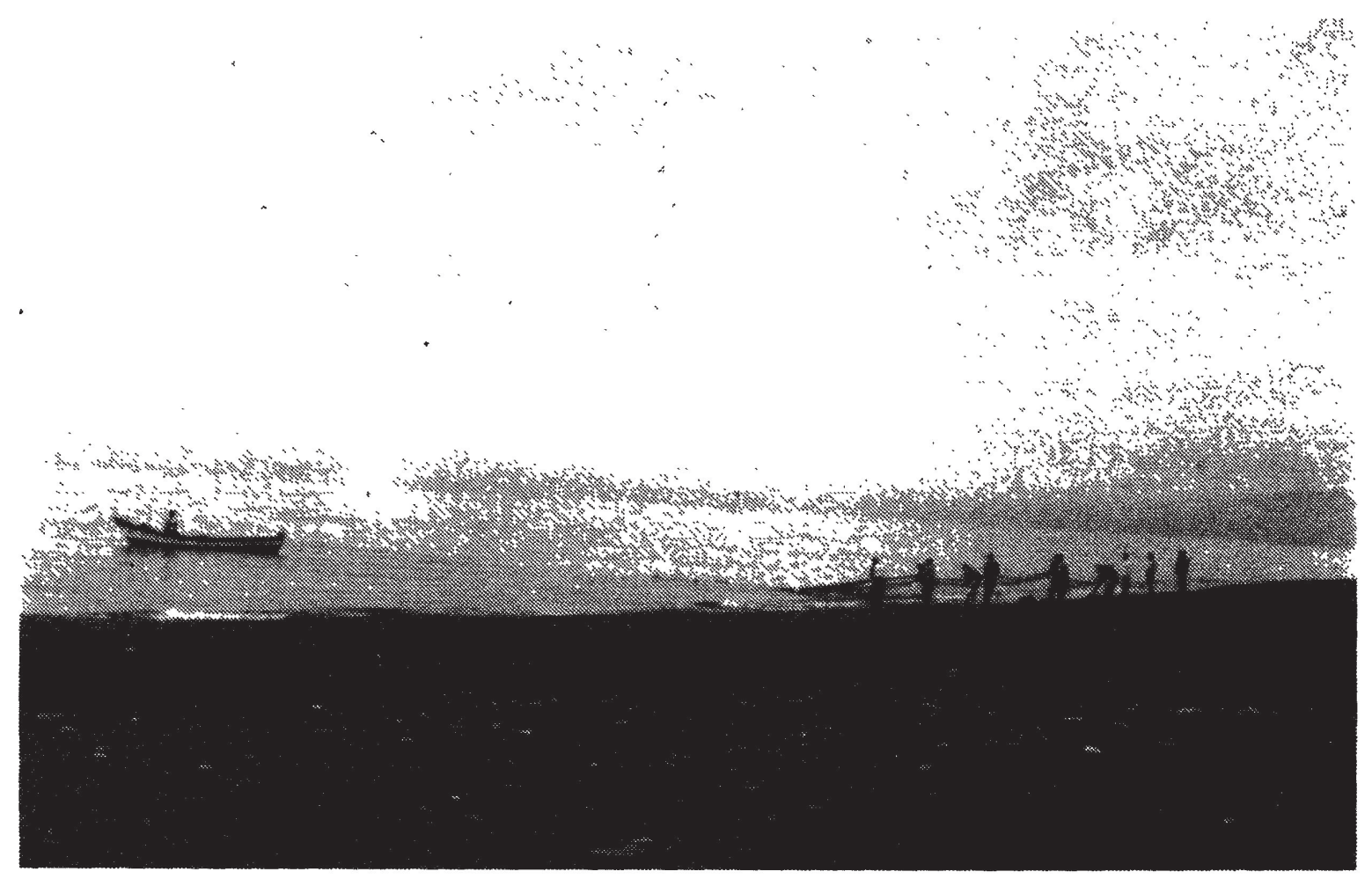

LÁm. I, b. Halando el copo en los caladeros de Benajarafe. 


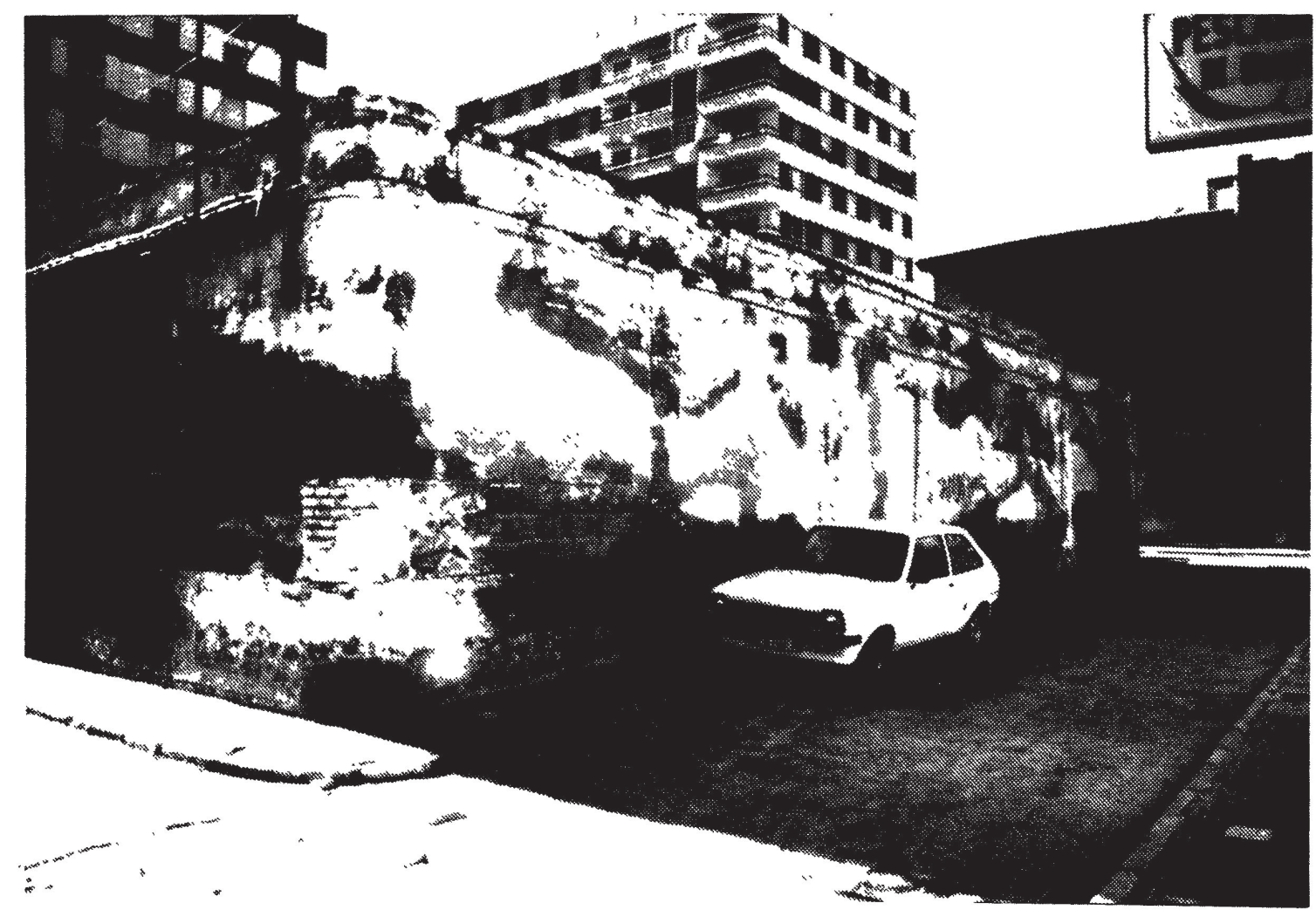

LÁM. II, a. El viejo Saladero, remozado a finales del XIX, constituye hoy un elemento anacrónico entre edificios turísticos (Torre del Mar, 1990).

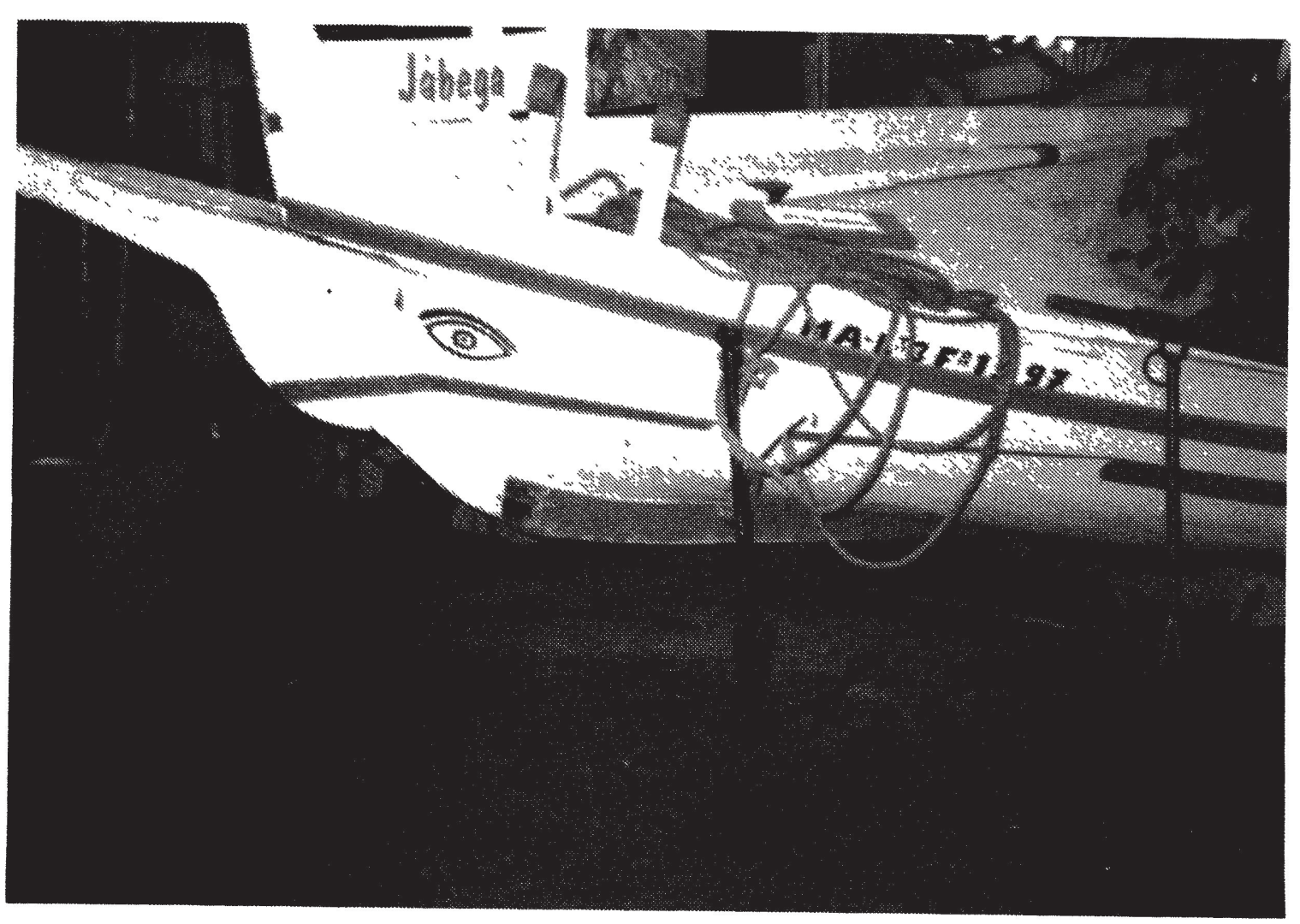

LÁM. II, b. Jábega del Rincón de la Victoria («I Feria de los Pueblos de la Axarquía», Vélez-Málaga, 1991). 